\title{
Fuzzy Time Series for Projecting School Enrolment in Malaysia
}

\author{
Nor Hayati Shafii ${ }^{1 *}$, Rohana Alias ${ }^{2}$, Siti Rohani Shamsudin ${ }^{3}$, Diana Sirmayunie Md Nasir \\ ${ }^{1,2,4}$ Faculty of Computer and Mathematical Sciences, \\ Universiti Teknologi MARA, Perlis Branch, Arau Campus,02600 Arau, Perlis, Malaysia
}

Corresponding author: *norhayatishafii@uitm.edu.my

Received Date: 18 January 2021

Accepted Date: 7 March 2021

Published Date: 14 March 2021

\section{HIGHLIGHTS}

- Fuzzy Time Series is used to develop models to forecast the number of school enrolments in Malaysia.

- Model is developed for the enrolment of pre-primary, primary, secondary, and tertiary school.

- The accuracy of the model is tested based on the value of mean squared error (MSE), Mean Absolute Percent Error (MAPE) and Mean Absolute Deviation (MAD).

\begin{abstract}
There are a variety of approaches to the problem of predicting educational enrolment. However, none of them can be used when the historical data are linguistic values. Fuzzy time series is an efficient and effective tool to deal with such problems. In this paper, the forecast of the enrolment of pre-primary, primary, secondary, and tertiary schools in Malaysia is carried out using fuzzy time series approaches. A fuzzy time series model is developed using historical dataset collected from the United Nations Educational, Scientific, and Cultural Organization (UNESCO) from the year 1981 to 2018. A complete procedure is proposed which includes: fuzzifying the historical dataset, developing a fuzzy time series model, and calculating and interpreting the outputs. The accuracy of the model is also examined to evaluate how good the developed forecasting model is. It is tested based on the value of the mean squared error (MSE), Mean Absolute Percent Error (MAPE) and Mean Absolute Deviation (MAD). The lower the value of error measure, the higher the accuracy of the model. The result shows that fuzzy time series model developed for primary school enrollments is the most accurate with the lowest error measure, with the MSE value being 0.38, MAPE 0.43 and MAD 0.43 respectively.
\end{abstract}

Keywords: Fuzzy time series, School Enrolments, Forecasting, Education Level, Accuracy.

\section{INTRODUCTION}

It is very crucial to make reasonably accurate forecasting of the future school enrolment in Malaysia because many decisions of the education system and resource planning will be made from them. For this reason, many researchers have proposed various methods to predict school enrolments. Fuzzy time series is one of the popular approaches used by researchers in forecasting problems due to its high accuracy and effectiveness compared to the other methods. It is an idea formulated by Song and Chissom proposed in 1993. It has many applications such as, forecasting wheat production (Stevenson \& Porter, 2009), forecasting rainfall distribution of a region (Dani \& Sharma, 2013), forecasting short-term electric load proposed by Huang (2015) and etc. 
A higher order fuzzy time series forecasting model based on adaptive expectation and ANN was suggested by Hakan et al., (2010). The forecasted values have been adjusted through adaptive expectation and feedforward neural network in ANN. Fuzzy relationships in the higher order fuzzy time series are defined easily using this approach. As a result, the forecasting precision has increased significantly as presented in the results. Chen et al., (2009) have used fuzzy time series in projecting the enrolments of the University of Alabama. The automatic clustering techniques and fuzzy logical relationships were used to analyse the data. This method has a higher accuracy with a smaller MSE value and was found to be more accurate than the previous methods. Mahdzar et al., (2015) used fuzzy time series in predicting the number of tourist arrivals in Sabah. The study was conducted to assist the government in effectively planning strategies that would maintain and increase the production of tourism in Malaysia. P. Ramesh \& K. Razak used a narrative time-invariant fuzzy time series for forecasting college admissions. They have found that fuzzy time series have significantly impact on achieving a better forecasting accuracy.

From the literature, we can see that researchers have used fuzzy time series in various fields. Therefore, this paper is carried out to show the application of fuzzy time series in projecting number of school enrolments in Malaysia.

\section{METHODOLOGY}

In this study, secondary data is taken from the United Nations Educational, Scientific, and Cultural Organization (UNESCO) institute. It consists of statistics of gross school enrolments in all stages of education in Malaysia from the year 1981 to 2018; a time-series data. The 35-years data from 1983 to 2018 is treated as the estimation period which is then used to forecast the number of school enrolments for the preceding years. The data is chosen just for simulation purposes to demonstrate the accuracy of the methods applied.

According to Hakan et al. (2014), fuzzy time series approach can deal with very small data and does not require the linearity assumption. This method makes the process of calculation become straightforward, (Dani \& Sharma, 2013) and easy to apply in so many problems. There are seven steps to be followed. It can be summarized as follows:

Step 1: All data for pre-primary, primary, secondary, and tertiary schools for the year 1981 until 2018 is imported into MS Excel. There are 38 sets of data for each educational level, thus there are 152 sets of data in total. The data is analysed and converted into percentage using MS Excel based on equation 1.1.

$$
y_{n}=\frac{\left(y_{n}-y_{n-1}\right)}{y_{n-1}} \times 100 \text {, }
$$

where, $y_{n}=$ total number of school enrolment in the current year, and $y_{n-1}=$ total number of school enrolment in the previous year. For example, the change of school enrolment from 1981 to 1982 was calculated according to equation (1.1) as follows:

$$
\text { Changes }_{1982}=\frac{30.55-21.73}{30.55} \times 100=40.59
$$

Step 2: Based on the calculation in Step 1, the universe of discourse, $U=\left[D_{\min }-D_{1}, D_{\max }+D_{2}\right]$ and dissolution $U$ is defined into $n$ with equal length of an interval as $u_{1}, u_{2}, \ldots u_{n}$. The value of $D_{\min }$ and 
$D_{\max }$ are identified to define $U$. Next, the universe of discourse is defined as $\left[D_{\min }-D_{1}, D_{\max }+D_{2}\right]$ where $D_{1}$ and $D_{2}$ are two proper positive numbers to be assigned in $U$. The actual values are shown in Table 1 below.

Table 1: The minimum value, maximum value, the value of $D_{1}$, and value of $D_{2}$ for all levels of education

\begin{tabular}{|c|c|c|c|c|}
\hline Level of education & Minimum value (\%) & Maximum value (\%) & Value of $D_{1}$ & Value of $D_{2}$ \\
\hline Pre-primary school & -24.57 & 49.46 & 5.43 & 0.54 \\
\hline Primary school & -1.72 & 2.94 & 0.28 & 0.06 \\
\hline Secondary school & -4.12 & 12.31 & 0.88 & 0.69 \\
\hline Tertiary school & -10.57 & 38.81 & 0.43 & 1.19 \\
\hline
\end{tabular}

Based on the values in Table 1, the universe of discourse, $U=\left[D_{\min }-D_{1}, D_{\max }+D_{2}\right]$, was determined in this step as shown in Table 2 .

Table 2: Table of universe of discourse

\begin{tabular}{|l|c|}
\hline \multicolumn{1}{|c|}{ Level of education } & Universe of discourse \\
\hline Pre-primary school & $U=[-30,50]$ \\
\hline Primary school & $U=[-2,3]$ \\
\hline Secondary school & $U=[-5,13]$ \\
\hline Tertiary school & $U=[-11,40]$ \\
\hline
\end{tabular}

Step 3: The fuzzy set $U_{i}$ is partitioned into several length intervals. In this study, $i$ can be anywhere in the range between 1 and 7 because the data in each education level are different every year. Then, the fuzzification of interval and the frequency distribution of each interval is calculated. The length of the interval for fuzzification is calculated using Equation (1.2).

$$
\text { Length of interval }=\frac{\left(D_{\max }+D_{2}\right)+\left(D_{\min }-D_{1}\right)}{7},
$$

The actual calculated values are as follows:

Length of interval for pre-primary school $=\frac{50-(-30)}{7}=11.43$

Length of interval for primary school $=\frac{3-(-2)}{7}=0.71$

Length of interval for secondary school $=\frac{13-(-5)}{7}=2.57$

Length of interval for tertiary school $=\frac{40-(-11)}{7}=7.29$

After that, the intervals are fuzzified, where the value of this length is added into each interval. The actual values of interval length for all education stage are presented in Table 3.

Table 3: The length of interval for pre-primary and primary school 


\begin{tabular}{|l|l|l|l|}
\hline$U_{1}=[-30.00,-18.57]$ & $U_{1}=[-2.00,-1.28]$ & $U_{1}=[-5.00,-2.43]$ & $U_{1}=[-11.00,-3.71]$ \\
\hline$U_{2}=[-18.57,-7.14]$ & $U_{2}=[-1.28,-0.57]$ & $U_{2}=[-2.43,0.14]$ & $U_{2}=[-3.71,3.57]$ \\
\hline$U_{3}=[-7.14,4.29]$ & $U_{3}=[-0.57,0.15]$ & $U_{3}=[0.14,2.71]$ & $U_{3}=[3.57,10.86]$ \\
\hline$U_{4}=[4.29,15.72]$ & $U_{4}=[0.15,0.86]$ & $U_{4}=[2.71,5.29]$ & $U_{4}=[10.86,18.14]$ \\
\hline$U_{5}=[15.72,27.15]$ & $U_{5}=[0.86,1.57]$ & $U_{5}=[5.29,7.86]$ & $U_{5}=[18.14,25.43]$ \\
\hline$U_{6}=[27.15,38.57]$ & $U_{6}=[1.57,2.29]$ & $U_{6}=[7.86,10.43]$ & $U_{6}=[25.43,32.71]$ \\
\hline$U_{7}=[38.57,50.00]$ & $U_{7}=[2.29,3.00]$ & $U_{7}=[10.43,13.00]$ & $U_{7}=[32.71,40.00]$ \\
\hline
\end{tabular}

After the fuzzification process, the frequency distribution is generated for each interval as shown in Table 4.

Table 4: Frequency distribution of each interval for pre-primary and primary school

\begin{tabular}{|c|c|c|c|c|}
\hline \multirow{2}{*}{ Intervals } & \multicolumn{4}{|c|}{ Numbers of data } \\
\cline { 2 - 5 } & Pre-primary school & Primary school & Secondary school & Tertiary school \\
\hline$U_{1}$ & 1 & 4 & 5 & 3 \\
\hline$U_{2}$ & 3 & 2 & 12 & 10 \\
\hline$U_{3}$ & 18 & 12 & 12 & 13 \\
\hline$U_{4}$ & 11 & 10 & 3 & 7 \\
\hline$U_{5}$ & 1 & 5 & 3 & 2 \\
\hline$U_{6}$ & 1 & 2 & 1 & 1 \\
\hline$U_{7}$ & 2 & 2 & 1 & 1 \\
\hline
\end{tabular}

The equal length of the interval is divided by the numbers of data for each interval. An example of calculation is shown below:

$v_{i}$ for Pre-primary school:

$v_{1}=[-30.00,18.57)$ with the length of 11.43 ,

$v_{2}=[-18.57,-14.76), \ldots, v_{4}=[-10.95,-7.14)$ with the length 3.81 , etc.

Step 4: The number of intervals will be following the number of linguistic variables which, in this study, used trapezoidal fuzzy sets $A_{1}, A_{2}, \ldots, A_{m}$ as represented below.

$A_{1}=\left[b_{0}, b_{1}, b_{2}, b_{3}\right]$,

$A_{2}=\left[b_{1}, b_{2}, b_{3}, b_{4}\right]$,

$A_{n}=\left[b_{n-1}, b_{n}, b_{n+1}, b_{n+2}\right]$.

An example of actual interval generated in fuzzy trapezoidal for pre-primary school is as follows:

$$
\begin{aligned}
& A_{1}=[-33.81,-30.00,-18.57,-14.76], \\
& A_{2}=[-30.00,-18.57,-14.76,-10.95], \\
& A_{3}=[-18.57,-14.76,-10.95,-7.14],
\end{aligned}
$$




$$
\begin{aligned}
& A_{36}=[27.15,38.57,44.29,50.00], \\
& A_{37}=[38.57,44.29,50.00,55.72] .
\end{aligned}
$$

Step 5: All the data is listed in percentage and being classified based on the interval that has been generated in Step 4. The fuzzy set $A_{i}$ shows a linguistics value and if the data is founded in the range of $v_{j}$, then it will be a fuzzy number, $A_{j}$. Then, the fuzzy logical relationships are generated based on the classified data. Fuzzy logical relation is symbolised as follows: $A_{i} \rightarrow A_{j}$,

where $A_{i}$ is the present state and $A_{j}$ is the upcoming state. The actual fuzzified data is produced and categorized into the corresponding fuzzy number as shown in Table 5.

Table 5: An example of fuzzified total school enrolment for pre-primary school

\begin{tabular}{|c|c|c|c|}
\hline Year & Total enrolment & Changes $(\boldsymbol{\%})$ & Fuzzified total enrolment \\
\hline 1981 & 21.73 & & \\
\hline 1982 & 30.55 & 40.59 & A37 \\
\hline 1983 & 32.64 & 6.84 & A26 \\
\hline 1984 & 33.12 & 1.47 & A19 \\
\hline. &. &. &. \\
\hline. &. &. & A 17 \\
\hline 2016 & 96.94 & -0.08 & A22 \\
\hline 2017 & 99.97 & 3.13 & A16 \\
\hline 2018 & 99.22 & -0.75 & \\
\hline
\end{tabular}

Then, fuzzy logical relationship is also constructed for all datasets. An example of logical relationship is shown in Table 6.

Table 6: Fuzzy logical relationship for pre-primary school

\begin{tabular}{|c|c|c|c|c|c|}
\hline$A_{37} \rightarrow A_{26}$ & $A_{5} \rightarrow A_{28}$ & $A_{37} \rightarrow A_{2}$ & $A_{10} \rightarrow A_{18}$ & $A_{5} \rightarrow A_{28}$ & $A_{23} \rightarrow A_{25}$ \\
\hline$A_{26} \rightarrow A_{19}$ & $A_{28} \rightarrow A_{13}$ & $A_{2} \rightarrow A_{4}$ & $A_{18} \rightarrow A_{18}$ & $A_{28} \rightarrow A_{35}$ & $A_{25} \rightarrow A_{23}$ \\
\hline$A_{19} \rightarrow A_{25}$ & $A_{13} \rightarrow A_{30}$ & $A_{2} \rightarrow A_{4}$ & $A_{18} \rightarrow A_{25}$ & $A_{35} \rightarrow A_{22}$ & $A_{23} \rightarrow A_{24}$ \\
\hline$A_{25} \rightarrow A_{12}$ & $A_{30} \rightarrow A_{19}$ & $A_{4} \rightarrow A_{24}$ & $A_{25} \rightarrow A_{27}$ & $A_{22} \rightarrow A_{21}$ & $A_{24} \rightarrow A_{17}$ \\
\hline$A_{12} \rightarrow A_{24}$ & $A_{19} \rightarrow A_{20}$ & $A_{36} \rightarrow A_{11}$ & $A_{27} \rightarrow A_{22}$ & $A_{21} \rightarrow A_{21}$ & $A_{17} \rightarrow A_{22}$ \\
\hline$A_{24} \rightarrow A_{5}$ & $A_{20} \rightarrow A_{37}$ & $A_{11} \rightarrow A_{10}$ & $A_{22} \rightarrow A_{5}$ & $A_{21} \rightarrow A_{23}$ & $A_{22} \rightarrow A_{16}$ \\
\hline
\end{tabular}

Step 6: Fuzzy relationship groups are generated in this step. The fuzzy logical relationships' rule is also arranged in groups as follows:

Table 7: Some of Fuzzy logical relationship based on their rule for pre-primary school

\begin{tabular}{|c|c|c|}
\hline Fuzzy set & Relationship & Rule \\
\hline$A_{37} \rightarrow A_{26}, A_{2}$ & One to many & Rule 3 \\
\hline
\end{tabular}




\begin{tabular}{|l|c|c|}
\hline$A_{26} \rightarrow A_{19}$ & One to one & Rule 2 \\
\hline$A_{19} \rightarrow A_{25}, A_{20}$ & One to many & Rule 3 \\
\hline$A_{25} \rightarrow A_{12}, A_{27}, A_{23}$ & One to many & Rule 3 \\
\hline. &. &. \\
\hline. & . & Rule 3 \\
\hline$A_{23} \rightarrow A_{25}, A_{24}$ & One to many & Rule 2 \\
\hline$A_{17} \rightarrow A_{22}$ & One to one & \\
\hline
\end{tabular}

Step 7: Each fuzzy relationship rule group is classified into one of the three different types of rule. The predicted production for each group is different according to the rule set. The rules involved in this step are shown as follows:

Rule 1: The fuzzy group of $A_{j}$ is empty, which means $A_{j}$ has no relationship with others. It can be represented as $A_{j} \rightarrow \emptyset$ or $A_{j} \rightarrow A_{j}$. The forecast value for this rule is $F_{v t}=R\left[\operatorname{NSTFN}\left(A_{j}\right)\right]$

Rule 2: The fuzzy group of $A_{j}$ is one to one, which means there is only one relationship with $A_{j}$ and can be written as $A_{j} \rightarrow A_{m}$. The forecast value is $F_{v t}=R\left[\operatorname{NSTFN}\left(A_{m}\right)\right]$.

Rule 3: The fuzzy group $A_{j}$ is one to many. For example: $A_{j} \rightarrow A_{m 1}, A_{j} \rightarrow A_{m 2}$ and $A_{j} \rightarrow A_{m 3}$. It is written as $A_{j} \rightarrow A_{m 1}, A_{m 2}, A_{m 3}$, and the forecast value will be calculated as follows:

$$
\begin{aligned}
& \operatorname{NSTFN}\left(A_{1}\right)=\left[\begin{array}{l}
t_{2}+\left[\frac{t_{4}-t_{1}}{4}\right]-\frac{t_{4}+t_{1}}{2}, t_{2}+\left[\frac{t_{4}-t_{1}}{4}\right], \\
\left.t_{3}+\left[\frac{t_{4}-t_{1}}{4}\right], t_{3}+\left[\frac{t_{4}-t_{1}}{4}\right]+\frac{t_{4}+t_{1}}{2}\right]
\end{array}\right] \\
& F_{v t}=R\left[\frac{\operatorname{NSTFN}\left(A_{m 1}\right)+\operatorname{NSTFN}\left(A_{m 2}\right)+\operatorname{NSTFN}\left(A_{m 3}\right)}{n}\right]
\end{aligned}
$$

where $n$ is the number of $A_{i}$ in this group.

\section{Example of Calculation for Step 7}

The data in this study are classified into two type of rules, which are Rule 2 and Rule 3. For Rule 2, the fuzzy logical relationship group for the year 1995 to 1996 is $A_{2} \rightarrow A_{4}$. Step 4 was repeated to get the trapezoidal number of $A_{4}$ using the following calculation:

$$
\begin{aligned}
& A_{4}=[-14.76,-10.95,-7.14,-6.51] \\
& t_{2}=-10.95 \\
& t_{3}=-7.14 \\
& t_{1}=-10.95-(-14.76) \\
& t_{4}=-6.51-(-7.14) \\
& =0.63
\end{aligned}
$$




$$
\begin{gathered}
\operatorname{NSTFN}\left(A_{4}\right)=\left[\begin{array}{l}
t_{2}+\left[\frac{t_{4}-t_{1}}{4}\right]-\frac{t_{4}+t_{1}}{2}, t_{2}+\left[\frac{t_{4}-t_{1}}{4}\right], \\
\left.t_{3}+\left[\frac{t_{4}-t_{1}}{4}\right], t_{3}+\left[\frac{t_{4}-t_{1}}{4}\right]+\frac{t_{4}+t_{1}}{2}\right] \\
=
\end{array}\right] \\
F_{v t}=\frac{-13.97+(-11.75)+(-7.94)+(-5.72)}{4} \\
=-18.57 \%
\end{gathered}
$$

Based on $F_{v t}$ which was calculated for the forecast value for the year 1996, the fuzzified total school enrolment for Rule 3 is:

$$
\begin{aligned}
& A_{19} \rightarrow A_{25}, A_{20} \\
& A_{25}=[5.33,6.37,7.4,8.44] \\
& t_{2}=6.37 \\
& t_{3}=7.4 \\
& t_{1}=6.37-5.33 \\
& t_{4}=8.44-7.4 \\
& =1.04 \\
& =1.04 \\
& A_{20}=[1.75,2.38,3.02,3.65] \\
& t_{2}=2.38 \\
& t_{3}=3.02 \\
& t_{1}=2.38-1.75 \\
& t_{4}=3.65-3.02 \\
& =0.63 \\
& =0.63 \\
& \operatorname{NSTFN}\left(A_{25}\right)=\left[\begin{array}{l}
t_{2}+\left[\frac{t_{4}-t_{1}}{4}\right]-\frac{t_{4}+t_{1}}{2}, t_{2}+\left[\frac{t_{4}-t_{1}}{4}\right], \\
\left.t_{3}+\left[\frac{t_{4}-t_{1}}{4}\right], t_{3}+\left[\frac{t_{4}-t_{1}}{4}\right]+\frac{t_{4}+t_{1}}{2}\right]
\end{array}\right] \\
& =[5.33,6.37,7.40,8.44] \\
& \operatorname{NSTFN}\left(A_{20}\right)=\left[\begin{array}{l}
t_{2}+\left[\frac{t_{4}-t_{1}}{4}\right]-\frac{t_{4}+t_{1}}{2}, t_{2}+\left[\frac{t_{4}-t_{1}}{4}\right], \\
\left.t_{3}+\left[\frac{t_{4}-t_{1}}{4}\right], t_{3}+\left[\frac{t_{4}-t_{1}}{4}\right]+\frac{t_{4}+t_{1}}{2}\right]
\end{array}\right] \\
& =[1.75,2.38,3.02,3.65]
\end{aligned}
$$

Then,

$$
\begin{aligned}
F_{v t} & =R\left[\frac{\operatorname{NSTFN}\left(A_{m 1}\right)+\operatorname{NSTFN}\left(A_{m 2}\right)+\operatorname{NSTFN}\left(A_{m 3}\right)}{n}\right] \\
F_{v t} & =R\left[\frac{5.33+1.75,6.37+2.38,+7.40+3.20,8.44+3.65}{2}\right] \\
& =[3.54,4.38,5.21,6.05]
\end{aligned}
$$




$$
\begin{aligned}
F_{v t} & =R\left[\frac{3.54+4.38+5.21+6.05}{4}\right] \\
& =4.79 \%
\end{aligned}
$$

The process is repeated to forecast the number school enrolments of the remaining fuzzy logical relationships groups.

\section{Accuracy Test}

In this study, the accuracy of the forecasted value is evaluated using Mean Square Error (MSE), Mean Absolute Percentage Error (MAPE) and Mean Absolute Deviation(MAD). The value of MSE is calculated using equation (1.5), MAPE using equation (1.6) and MAD using equation (1.7).

$$
\begin{aligned}
& e_{t}=y_{t}-\hat{y}_{t}, \\
& M S E=\frac{\sum_{t=1}^{n} e_{t}^{2}}{n},
\end{aligned}
$$

where, $y_{t}=$ the actual value of total school enrolment at time $t, \hat{y}_{t}=$ the forecasted value of total school enrolment and $n=$ numbers of data. The values of MAPE, MSE and MAD are analyzed based on the lowest value of error measure.

\section{FINDINGS AND DISCUSSIONS}

The forecasted values in percentage are changed into the total value of the school enrolments. Table 8 shows the comparison between the actual number of school enrolments and the forecasted values for each year using FTS for all levels of schools in Malaysia. The forecasted value for the year 1981 and 1982 cannot be evaluated because there is no previous input data for these two years.

Table 8: The forecasted value for Pre-primary, Primary, Secondary and Tertiary school

\begin{tabular}{|c|c|c|c|c|c|c|c|c|}
\hline \multirow{2}{*}{ Years } & \multicolumn{2}{|c|}{ Pre-primary School } & \multicolumn{2}{|c|}{ Primary School } & \multicolumn{2}{c|}{ Secondary School } & \multicolumn{2}{c|}{ Tertiary School } \\
\cline { 2 - 9 } & $\begin{array}{c}\text { Total } \\
\text { enrolment }\end{array}$ & $\begin{array}{c}\text { Forecasted } \\
\text { value }\end{array}$ & $\begin{array}{c}\text { Total } \\
\text { enrolment }\end{array}$ & $\begin{array}{c}\text { Forecasted } \\
\text { value }\end{array}$ & $\begin{array}{c}\text { Total } \\
\text { enrolment }\end{array}$ & $\begin{array}{c}\text { Forecasted } \\
\text { value }\end{array}$ & $\begin{array}{c}\text { Total } \\
\text { enrolment }\end{array}$ & $\begin{array}{c}\text { Forecasted } \\
\text { value }\end{array}$ \\
\hline 1981 & 21.73 & & 96.34 & & 57.19 & & 3.82 & \\
\hline 1982 & 30.55 & & 95.91 & & 57.33 & & 3.99 & 4.33 \\
\hline 1983 & 32.64 & 28.92 & 95.51 & 95.85 & 60.79 & 62.14 & 4.27 \\
\hline 1984 & 33.12 & 33.31 & 95.27 & 95.45 & 62.97 & 65.83 & 4.32 & 4.34 \\
\hline 1985 & 35.19 & 34.71 & 95.64 & 96.07 & 63.18 & 63.06 & 4.81 & 4.86 \\
\hline 1986 & 34.12 & 36.54 & 96.33 & 96.45 & 69.25 & 68.48 & 5.72 & 5.23 \\
\hline 1987 & 35.64 & 36.12 & 95.9 & 95.98 & 68.06 & 68.46 & 6.73 & 7.35 \\
\hline 1988 & 32.95 & 39.58 & 96.11 & 95.84 & 66.33 & 67.47 & 7.35 & 7.40 \\
\hline 1989 & 35.79 & 36.25 & 94.69 & 94.83 & 65.39 & 65.85 & 7.38 & 7.41 \\
\hline 1990 & 34.86 & 41.10 & 94.79 & 95.23 & 63.41 & 63.58 & 6.6 & 6.84 \\
\hline 1991 & 38.86 & 39.07 & 94.61 & 94.94 & 64.53 & 64.65 & 7.18 & 7.22 \\
\hline 1992 & 39.42 & 39.66 & 94.4 & 94.54 & 65.61 & 64.69 & 7.88 & 7.95 \\
\hline 1993 & 40.11 & 41.31 & 95.37 & 95.19 & 64.53 & 65.77 & 8.91 & 9.54 \\
\hline 1994 & 59.95 & 59.02 & 96.53 & 96.40 & 64.78 & 63.97 & 9.22 & 8.96 \\
\hline 1995 & 45.22 & 56.76 & 97.15 & 97.12 & 64.82 & 66.43 & 10.14 & 10.21 \\
\hline 1996 & 40.02 & 40.77 & 97.25 & 97.33 & 66.43 & 66.61 & 12.97 & 12.28 \\
\hline 1997 & 41.95 & 42.36 & 97.48 & 97.40 & 70.01 & 70.80 & 15.59 & 14.88 \\
\hline 1998 & 56.54 & 46.59 & 97.82 & 97.16 & 78.63 & 75.81 & 21.64 & 20.03 \\
\hline 1999 & 54.5 & 54.84 & 96.14 & 96.30 & 77.85 & 77.73 & 22.62 & 24.83 \\
\hline 2000 & 52.05 & 52.51 & 95.86 & 96.01 & 77.41 & 77.54 & 25.62 & 24.19 \\
\hline
\end{tabular}

Copyright@ 2021 UiTM Press. This is an open access article under the CC BY-NC-SA (https://creativecommons.org/licenses/by-nc-sa/4.0//) 


\begin{tabular}{|l|l|l|c|c|c|c|c|c|}
\hline 2001 & 52.38 & 52.79 & 98.68 & 96.98 & 76.9 & 77.44 & 25 & 25.77 \\
\hline 2002 & 52.67 & 54.56 & 98.08 & 98.54 & 77.02 & 76.92 & 27.44 & 26.89 \\
\hline 2003 & 55.68 & 54.86 & 96.6 & 97.49 & 82.9 & 83.48 & 30.61 & 33.23 \\
\hline 2004 & 59.86 & 61.84 & 97.37 & 97.15 & 84.13 & 84.35 & 30.03 & 33.27 \\
\hline 2005 & 61.89 & 62.30 & 99.72 & 100.12 & 80.66 & 83.07 & 27.92 & 28.42 \\
\hline 2006 & 57.19 & 61.04 & 99.99 & 99.58 & 79.73 & 79.82 & 28.41 & 28.80 \\
\hline 2007 & 62.04 & 62.91 & 98.69 & 99.66 & 77.48 & 79.47 & 30.01 & 30.14 \\
\hline 2008 & 74.40 & 71.25 & 97.95 & 98.08 & 77.11 & 76.93 & 33.44 & 33.74 \\
\hline 2009 & 76.91 & 77.43 & 97.98 & 97.36 & 76.12 & 76.72 & 35.49 & 36.35 \\
\hline 2010 & 79.14 & 75.85 & 98.66 & 98.72 & 77.27 & 75.87 & 37.03 & 37.25 \\
\hline 2011 & 81.23 & 82.40 & 99.76 & 99.86 & 77.47 & 76.30 & 36.15 & 39.59 \\
\hline 2012 & 84.67 & 84.58 & 101.08 & 100.84 & 81.48 & 83.97 & 37.61 & 38.88 \\
\hline 2013 & 89.41 & 90.06 & 102.74 & 103.21 & 81.87 & 82.03 & 39.07 & 38.74 \\
\hline 2014 & 93.01 & 92.83 & 104.66 & 103.75 & 85.35 & 83.96 & 39.51 & 40.24 \\
\hline 2015 & 97.02 & 98.93 & 104.36 & 105.69 & 84.93 & 85.47 & 45.59 & 46.06 \\
\hline 2016 & 96.94 & 107.75 & 103.82 & 105.58 & 84.71 & 84.50 & 46.76 & 47.03 \\
\hline 2017 & 99.97 & 100.89 & 105 & 105.08 & 85.45 & 85.65 & 43.72 & 44.26 \\
\hline 2018 & 99.22 & 98.60 & 105.29 & 106.13 & 81.99 & 82.84 & 45.13 & 45.09 \\
\hline
\end{tabular}

Figure 1 illustrates the ups-and-down movement of the data between the actual and the forecasted values. The horizontal axis of the graph displays the timeframe from the year 1981 to 2018 and the vertical axis represents the total numbers of school enrollments. In overall movement, it shows that most of the forecasted values are closest to the actual data. Hence, to be more specific, the error values are calculated.

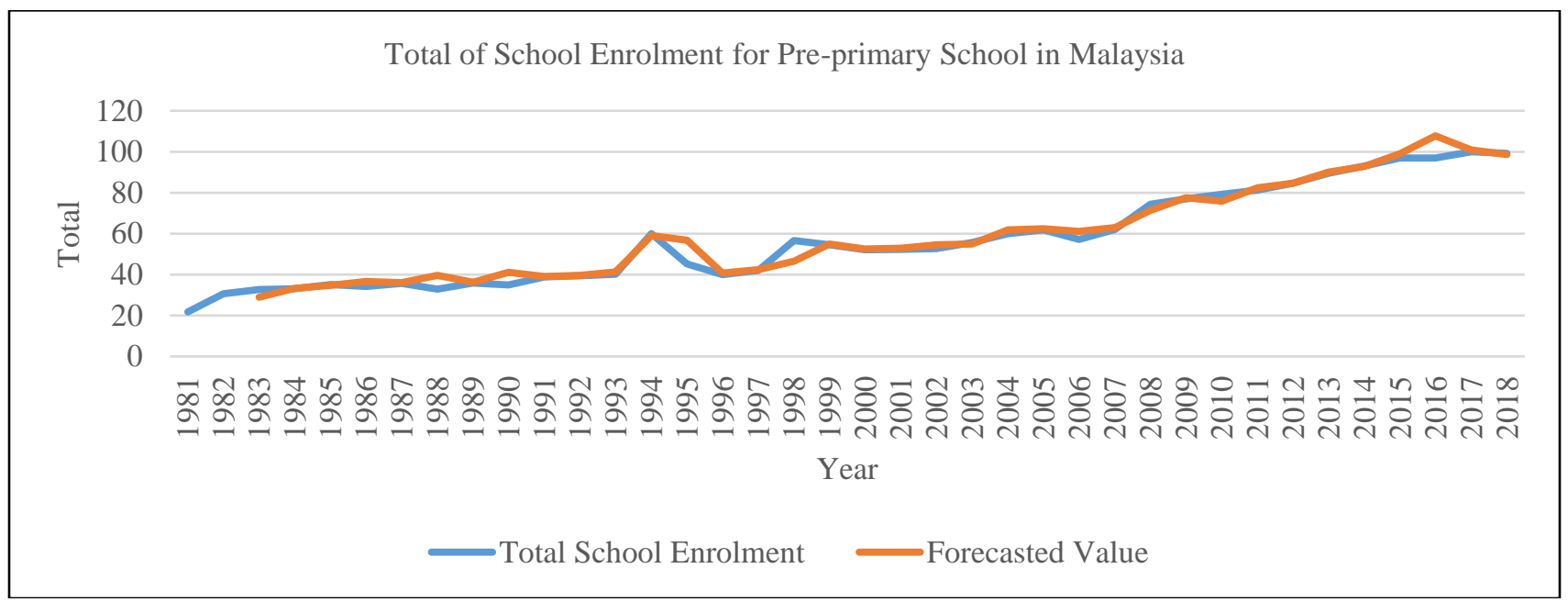

Figure 1: The graph of the actual and forecasted value for pre-primary school

Table 9 shows the values of MSE, MAPE and MAD for four different level of education.

Table 9: The value of MSE, MAPE and MAD

\begin{tabular}{rl|c|c|c|}
\hline Education Level & MSE & MAPE & MAD \\
\hline Pre-primary & 14.10 & 4.4 & 2.23 \\
\hline
\end{tabular}




\begin{tabular}{|c|c|c|c|}
\hline Primary & 0.38 & 0.43 & 0.43 \\
\hline Secondary & 1.39 & 1.19 & 1.68 \\
\hline Tertiary & 1.28 & 3.35 & 0.72 \\
\hline
\end{tabular}

The model for primary school enrolment has produced the lowest MSE, MAPE and MAD which are 0.38, 0.43 and 0.43 respectively. This indicates that the forecasted values of fuzzy time series model are most accurate for the data of primary school enrolment. Meanwhile the highest error was produced for the data of Pre-primary school. This result might be affected by the situation where the enrolments of children for pre-primary schools are influenced by many unpredictable factors.

\section{CONCLUSION AND RECOMMENDATIONS}

The important part of the prediction is identifying the smallest error to determine the most accurate mathematical model that can fit the actual data. In this study, fuzzy time series approach is used to generate the mathematical model of school enrolment for pre-primary, primary, secondary, and tertiary school in Malaysia from 1981 to 2018. The actual data and the forecasted data are analyzed to determine the difference between these two data. By calculating the lowest value of MSE, MAPE and MAD for each stage of education, the mathematical model with the best accuracy was determined. The best result came from the model constructed for the data of primary school enrolment which has the lowest values of MSE, MAPE and MAD which are $0.38,0.43$ and 0.43 respectively. In overall, the values of error measures of model for all education level are still reasonable and acceptable, indicating that fuzzy time series approach is an effective and accurate way to predict the number of school's enrolments.

This study has been done with only one method which is fuzzy time series approach. In future it might be possible to analyze the same data by using other approaches such as Artificial Neural Network (ANN) or a hybrid method which is a combination of two different models, which might produce a better result.

\section{REFERENCES}

Chen, S. M. (2002). Forecasting enrollments based on high-order fuzzy time series. Cybernetics and Systems. https://doi.org/10.1080/019697202753306479

Dani, S., \& Sharma, S. (2013). Forecasting rainfall of a region by using fuzzy time series. Asian Journal of Mathematics and Applications, 2013(1), 1-10.

Hakan, C., Egrioglu, E., Yolcu, U., \& Uslu, V. R. (2014). A high order seasonal fuzzy time series model and application to international tourism demand of Turkey, Journal of Intelligent \& Fuzzy Systems, 26, 295-302. https://doi.org/10.3233/IFS-120738 Chen et al.

Hakan, C., Yolcu, U., \& Egrioglu, E. (2010). A high order fuzzy time series forecasting model based on adaptive expectation and artificial neural networks. Mathematics and Computers in Simulation, 81(4), 875-882. https://doi.org/10.1016/j.matcom.2010.09.011

Huang, Y. (2015). Weighted Fuzzy Time Series Model for Load Forecasting. NCITPA, 81-90.

Mahdzar, M., Ling, S. M., Nair, M. B., \& Shuib, A. (2015). Forecasting tourist arrivals to Sabah using fuzzy time series. International Conference on Natural Resources, Tourism and Services Management 2015 . 
Ramesh, P., Razak, K. (2018). Forecasting Enrollment using Fuzzy Time Series. International Journal of Pure and Applied Mathematics, 2018(15), 3309- 3313

Stevenson, M., \& Porter, J. E. (2009). Fuzzy Time Series Forecasting Using Percentage Change as the Universe of Discourse. World Academy of Science, Engineering and Technology, 55, 154-157. 